\title{
Study on the Security Capability, the Security Planning and the Security Mechanism of Rural House in China
}

\author{
Feng Han \& Yachen Liu \\ School of Management, Shenyang Jian Zhu University, Shenyang 110168, China \\ E-mail: hanf606@163.com
}

The research is financed by the Liaoning Provincial Social Science Layout Fund (No.L07BJY041). (Sponsoring information)

\begin{abstract}
The concept and connotation of rural house are first defined in the article, and the main factors and main contents of the security capacity of rural house are proposed. Second, aiming at the contents of the rural house security capability, the concept and meanings of rural house security planning are researched, and the general principals and basic objectives of rural house security planning are proposed, and the content frame of the rural house security planning is confirmed. Finally, the corresponding security mechanism of the rural house security planning is proposed in the article.
\end{abstract}

Keywords: Rural house, Security capability, Security planning, Security mechanism

At present, most research results about the disaster reduction and prevention aim at reducing the economic losses induced by natural disasters such as flood, earthquake and storm to the largest extent, and ensuring the security of people's lives and properties and the normal implementation of economic construction. Because of the importance of rural house for farmers' production, living and property, many researches can be classed in the domain of rural house security capacity. Nowadays, the rural house security capacity has been the comprehensive research domain for many subjects, and the main research views include following five aspects. First, some early researches proposed to implement the comprehensive disaster prevention technical measures and the post-disaster emergency rescue plan in the rural construction, and establish the macro control system of comprehensive disaster prevention in the rural construction layout (Ge, 1996, P.27-28 \& Ge, 1996, P.42-44). The second aspect is the researches about the subsystem in the disaster prevention and reduction system. And they include the applications of the information integration technology and the GIS technology in the disaster prevention management system (Fu, 2005, P.20-22 \& Shi, 2007, P.47-51), and the improvement of the management system (Chen, 2006, P.12-13). The third aspect is the researches about the structured improvement and countermeasures aiming at various disasters in various periods, from the single disaster prevention improvement from the structure (Wang, 1992, P.22-23 \& Cui, 2004, P.41-44) to the implementation of the disaster reduction and comfortable housing project (Lu, 2007, P.28-29). The fourth aspect is the research contents and methods about the disaster evaluation (Sun, 2001, P.122-130). The fifth aspect is to begin to emphasize the research results of foreign disaster prevention measures (Bao, 2001, P.34-36 \& Lu, 2008, P.39-40).

Above research results only studied the security capacity of rural house from some layers and parts, and they didn't comprehensively and completely research this problem. Though there are many disaster prevention countermeasures, but the security planning and the security mechanism design of rural house have not been proposed from the special angle of the security capacity of rural house. Therefore, based on the summarization of above research results, the establishment of the security capacity, the security planning and the security mechanism for rural house are systematically proposed in the article as follows.

\section{The concept and main contents of rural house security capability}

\subsection{The concept of rural house security capability}

The security capacity of rural house means the comprehensive capacity of rural house avoiding being damaged by disasters and ensuring villagers' life and property to the largest extent. 


\subsection{Main contents of rural house security capability}

\subsubsection{Disaster prevention capability}

Combining with main development trend of domestic disaster prevention and reduction works, and using domestic and foreign disaster prevention and reduction research results for references, the disaster prevention capacity of Chinese rural house is proposed, and it includes the monitoring and warning capacity, the planning capacity and the post-disaster reconstruction capacity. The post-disaster reconstruction is the important development to enhance the disaster prevention capacity of rural house, and it is a new cycle of disaster prevention and reduction, so it is ranked in the disaster prevention capacity.

The monitoring and warning capacity mainly includes the disaster monitoring and warning capacities (all-the-time monitoring capacity and the short-term timely warning capacity) of various relative departments, the warning capacity of the village to some disasters (such as fire), the ability to inform relative personnel for the information coming from superior government, and perfect infrastructures (TV, telephone and network).

The planning capacity mainly means that the rural house should be planed as a whole, accord with national standard of construction technology and possess reasonable position of infrastructure, and the rural house can effective serve for the whole town.

The post-disaster reconstruction capacity mainly includes the quick evaluation capacity, the repairing capacity and the renovating capacity of rural house after disaster. The post-disaster quick evaluation capacity of rural house is to quickly evaluate the damage rate of rural houses after disaster ends according to the judgment standards and criterions of damage, and take the evaluation results as the premise and references for the post-disaster recovering and reconstruction. The repairing capacity is the capacity to repair the damaged houses with reasonable planning, and the renovating capacity is to renovate the seriously damaged houses with reasonable planning, and gradually renovate the damaged houses with reasonless planning, and make them to reach the planning standard. Aiming at the national situation of China, the present renovating ability is the emphasis of the development.

\subsubsection{Disaster resistant ability}

The disaster resistant ability means the ability to resist the disaster, and it mainly includes the disaster tracing analysis ability and the quick reaction capability.

(1) Basic contents

The disaster tracing analysis ability is the ability to exactly collect and analyze the disaster development information after disaster happens.

The quick reaction ability is mainly to do the preparation works after the disaster warning occurs and after the disaster happens, trace and analyze the relative information of disaster, and make effective and timely countermeasures.

(2) Emphases and applied range of two kinds of abilities

The disaster tracing analysis ability is applied in the large-scale disaster, because many disasters belong to the disasters with long-term damages or instant damages, and only the manpower can not resist thus large-scale disaster, but people can trace and analyze the disaster to know the characters of disaster in various stages, and establish the disaster resistant measures.

The quick reaction ability is applied in the fire or other disasters with small damages. For these disasters, when the infrastructure is self-contained, the quick reaction ability is the key to resist the disaster.

\section{Concept, meanings and main contents of rural house security planning in China}

The security planning of rural house is the key measure to ensure and enhance the security capacity of rural house, and the works and effects of disaster prevention and reduction for rural house security capacity are embodied by the implementation of the rural house security planning. Therefore, the rural house security planning according with local actual situation and its practical implementation are the key to protect people's life and property for rural houses in the disaster prevention and resistant actions.

\subsection{Concept and meanings of rural house security planning in China}

\subsubsection{Concept of rural house security planning in China}

Aiming at the contents and evaluation system of the rural house security capacity, the rural house security planning is a new parallel planning integrating management design and practical planning for the actual construction of rural house, management mechanism, management mode, and disaster prevention and reduction, which could enhance the rural house security capacity through aiming at the key factors about the security of rural house. 


\subsubsection{Meanings of rural house security planning in China}

The rural house security planning has two meanings, and the one is the construction planning of house and infrastructure matching with the rural house security to enhance the security capacity, and the other one is the management design planning of rural house security. The construction planning of house and infrastructure matching with the rural house security is the material planning, and it is the premise and material base to realize the rural house security capacity and it is "visible security guarantee". The management design planning is the system guarantee to implement the rural house security planning and it is "invisible security guarantee".

\subsection{General principles and basic targets to make the rural house security planning}

\subsubsection{General principles to make the rural house security planning}

(1) The rural house security planning should accord with the exiting policies, laws and standards in China.

(2) China has a vast territory, and differences among different regions are obvious, so the rural house construction should possess different characters according to local economy, customs, habits, and building materials. The rural house security planning should give prominence to local characters and can not require simple identical standard.

(3) According to the concrete situations of the local place, the main disaster should be selected as the maim object for the rural house security planning, and other disasters should also be properly considered at the same time.

(4) The guideline giving priority to disaster prevention and combining prevention with resistant measures should be implemented.

\subsubsection{Basic targets to make the rural house security planning}

The basic targets include gradually enhancing the security capacity of rural house, reducing the economic losses induced by various natural disasters to the largest extent, and guaranteeing people's security of life and property in the disaster. When the village suffers the forecasted disaster (such as the flood or the earthquake), the rural houses in the village are not damaged seriously without personnel casualty. In addition, when the disaster is serious, the life line project including water, electricity, food and medical treatment can be recovered as soon as possible, and there are safe public buildings which can be used to take care of peoples in the disaster.

\subsection{Main content frame of rural house security planning in China}

\subsubsection{Construction layout of rural house and security matched infrastructure}

The construction of rural house should enhance the disaster prevention and reduction capacity aiming at local main disasters.

(1) The spatial planning of rural house should be emphasized in the construction.

(2) Aiming at the character that most of construction of rural house all uses local materials, the technical method and intension standard to reinforce the local construction materials should mainly consider the characters of local materials.

(3) The classic construction standards of rural house structure should be established according to local disaster type and main disaster.

(4) The matched security infrastructure should be planned with the rural house, and the scale and service ability of matched infrastructure should take the scale of rural house as the standard, and consider that the location should ensure quickly serving all direction of rural house, and the location of matched infrastructure is advised to located in the geometric center of the rural houses.

(5) The communication establishments including information and network should be constructed, and the disaster resistant class of the communication establishment should be enhanced, or the communication establishment with strong disaster resistant capacity should be added to ensure the information transfer when disaster happens.

\subsubsection{Layout of management and design}

The layout of management and design includes the disaster prevention capacity management mechanism and flow design, and the disaster resistant management mechanism and flow design. The contents of each part all correspond with the rural security capacity.

(1) The disaster prevention capacity management mechanism and flow design includes the monitoring and warning management mechanism and flow design, the management mechanism and flow design of house building structure technology standard, the drumbeating education scheme and management mechanism, the post disaster quick evaluation management mechanism and flow design, and the post-disaster repairing and reconstruction management mechanism and flow design.

(2) The disaster resistant management mechanism and flow design includes the disaster information tracing and analysis management mechanism and flow design, the pre-disaster quick reaction management mechanism and flow design, and 
the disaster quick reaction management mechanism and flow design.

\section{Matched security mechanism design of rural house security planning in China}

Though the rural house security planning is a compelling standard, but there must be necessary guarantee measures to make it implemented reasonably and favorably.

\subsection{System of construction quality management}

Aiming at the confusion of rural house construction in China, the management of construction quality should be urgently strengthened.

\subsection{Encouragement of architecture technology innovation and extension}

Various-level construction technology design departments, colleges and scientific research institutions should be encouraged to cooperate with local district through various modes and put forward the house technical design and technical standards with local characters. Based on that, the technology should combine with the building custom and styles, and develop to the direction with economy, saving, friendly environment and good security. At the same time, the excellent construction technologies should be largely extended to make them be understood and accepted by farmers.

\subsection{Regulations about legal status of rural house security planning in China}

The legal status of rural house security planning should be guaranteed, which can ensure the rural house security planning to be implemented in practice and enhance the rural house security substantially.

\subsection{System of rural house security planning supervision in China}

The special supervision department should be established for the rural house security planning to supervise the establishment and implementation process and result and ensure the science, rationality and application of the security planning.

\subsection{Establishment of Chinese national disaster prevention organization}

(1) Before the disaster happens, various reasonable modes should be utilized to store resources such as capitals and materials.

(2) The financial management organization should be established, and it functions include preparing capitals, integrating the beneficences from various institutions, operating various post-disaster insurance compensation, and supervising relative lower units.

\subsection{Emergency organizing and planning system in disaster and post disaster}

When the disaster happens, people should make reactions quickly, establish rescue plans, and implement various measures for disaster reduction, distribute personnel, capitals and relative materials. Only under the premise with perfect organization, everything will be completed highly effectively.

\subsection{Construction personnel's training system for rural house}

The survey results for rural house indicate that most construction personnel of rural house are local nonprofessional personnel, such as householders, householders' relatives and friends, bricklayers and plasterers in the village. These personnel can be selectively trained periodically or non-periodically, so they can transfer the professional knowledge and technical standards to others in the construction, which can gradually enhance the construction quality of rural house by enhancing construction personnel's quality and knowledge level.

\subsection{Innovation of rural house insurance financing mode}

Aiming at the actuality of farmers' low insurance rate, according to farmer's economic income level and present psychology, the rural house insurance financing mode should be innovated, for example, the insurance mode of "one Yuan in one year" can be pushed in the national range to share the risk equally according to the regional character and frequency of large-scale disaster.

\subsection{Perfection of Chinese relative laws and regulations}

A series laws and regulations about disaster prevention and reduction should be established and perfected to punish those behavior subjects with serious mistake, serious fault and problems in the disaster prevention and disaster resistant process. For example, the enterprises or persons with commercial fraud and hoarding behaviors must be chastised in the disaster relief work. 


\section{References}

Bao, Junqiang. (2001). Disaster Prevention Countermeasures in Korea. Overview of Disaster Prevention. No.12, P. 34-36.

Chen, Xiaohui. (2006). Xiamen Typhoon Disaster and Countermeasures of Disaster Prevention and Reduction in 2006. China Flood \& Drought Management, No.4, P.12-13.

Cui, Ying, Wang, Yihong, Shi, Jian \& Chi, Jiaxiang. (2004). Evaluation of Seismic Behavior of Old Buildings in Cities. Earthquake Resistant Engineering and Retrofitting, No. 6, P. 41-44.

$\mathrm{Fu}$, Jiande \& Xu, Gang. (2005). Application of GIS in the Rural House Disaster Prevention Management Information System. Zhejiang Mapping, No. 4, P. 20-22.

Ge, Xueli \& Li, Yuping. (1996). Comprehensive Disaster Prevention Technical Measure and Post-disaster Emergency Rescue Plan in the Construction of Village and Small Town. Construction of Small Town, No. 4, P. 27-28.

Ge, Xueli \& Li, Yuping. (1996). Macro Control of Comprehensive Disaster Prevention in the Village and Small Town Construction Planning. Disaster Reduction in China, No. 6(4), P. 42-44.

Lu, Kunsheng \& Yu, Zunping. (2007). It Is Imperative under the Situation to Implement the Disaster Reduction and Housing Project: Investigation of Rural Housing Environment and Housing Situation in Fuzhou City in Jiangxi Province. Disaster Reduction in China, No.12, P. 28-29.

Lu, Zhenheng \& Zhang, Gexian. (2008). The Stress of Countermeasures to Earthquake Prevention and Disaster Mitigation in Japan in 2008. Recent Developments in World Seismology, No.1, P. 39-40.

Shi, Lihong, Su, Bin \& Zhang, Qingpu. (2007). Study on Integration Method of Disaster Control and Reduction System. Geomatics World, No.1, P. 47-51.

Sun, Shaopin. (2001). A Study on the Contents and Methods of Disaster Assessment. Progress in Geography, No.2, P. 122-130.

Wang, Jingyi, Wang, Guiqiu \& Wang, Xiangzhan. (1992). Study on the Anti-earthquake and Disaster Prevention in Rural House Construction. Construction of Small Town, No. 3, P. 22-23. 